\title{
HALLAZGOS BIOQUÍMICO-HISTO-MORFOMÉTRICOS DE LA PRÓSTATA RESIDUAL (III): PSA "INDETECTABLE" MANTENIDO TRAS ADENOMECTOMÍA RETROPÚBICA POR HBP
}

\author{
Juan José Ballesteros Sampol, Javier Gimeno Beltrán y Lluís Fumadó Ciutat.
}

Servicios de Urología y UQTR y Patología de los Hospitales del I.M.A.S. Instituto Municipal de Asistencia Sanitaria. Hospital Nuestra Señora de la Esperanza y Hospital Nuestra Señora del Mar. Barcelona. España.

\begin{abstract}
Resumen.- OBJETIVO: La presentación de 4 casos que, intervenidos de adenomectomía retropúbica por HBP, han presentado, en los controles postoperatorios de PSA, cifras "indetectables" del antígeno (PSA<0.15ng/ mll, de forma mantenida a largo plazo.
\end{abstract}

MÉTODO: Proceden de una serie de 70 casos consecutivos intervenidos por vía abierta de HBP que han venido siendo seguidos y controlados, a nivel hospitalario, en sus aspectos bioquímico, histológico y morfométrico durante los 5 años siguientes a la intervención.

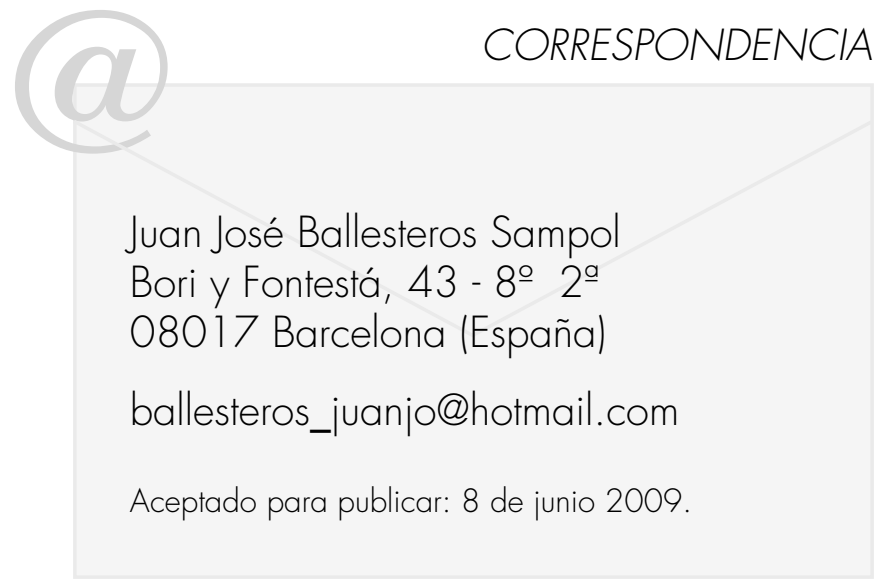

RESULTADOS: Cuatro pacientes han demostrado cifras de PSA < 0.15 en todos los controles que se han establecido a partir de la cirugía hasta el momento presente en el que, en conjunto, supone una media de seguimiento de 45,25 meses. Ha existido una concordancia de esta determinación con los datos morfométricos e histológicos, cuando se han conseguido.

CONCLUSIÓN: La "indetectabilidad" del PSA después de adenomectomía prostática abierta podría suponer un fiable marcador de seguimiento para descartar la neohiperplasia equivalente a la expresión de "cura radical" de la HBP.

Palabras clave: PSA. Adenomectomía retropubica. HBP.

Summary.- OBJECTIVES: To present 4 cases with "undetectable" PSA levels (PSA $<0.15 \mathrm{ng} / \mathrm{mll}$ on longterm postoperative follow-up after retropubic adenomectomy for $\mathrm{BPH}$

METHODS: They come from a series of 70 consecutive cases of retropubic prostatic adenomectomies, monitored and controlled at the hospital in their biochemical, histological and morphometric analysis for 5 years following the intervention.

RESULTS: Four patients have demonstrated PSA levels $<0.15$ in all controls after surgery. Mean follow-up of the global series: 45.25 months. There is correlation between this determination and histological and morphometric data, when they were achieved. 
CONCLUSIONS: "Undetectable" PSA after open prostatic adenomectomy could be an equivalent to the expression of "radical cure" of BPH, and a reliable marker for monitoring neo-hyperplasia.

Keywords: PSA. Retropubic adenomectomy $\mathrm{BPH}$.

\section{INTRODUCCIÓN}

La aplicación clínica del PSA, desde la década de los 80, ha venido a significar el mejor instrumento que poseemos para el diagnóstico precoz del cáncer de próstata aún con los inconvenientes que en no pocos casos provoca su insuficiente especificidad. Pero no sólo lo estamos aplicando en esta patología prostática sino también en HBP (gran productora de PSA) como lo han expresado conocidos estudios que establecen los parámetros para orientar la progresión de la misma (RAO y/o cirugía) sobre la base del volumen prostático y el mencionado antígeno (1).

Desde hace unos años hemos establecido nuestro interés en la llamada "próstata residual" resultante de la enucleación operatoria por HBP. Es un tema poco abordado en la literatura pero, el hecho de la espectativa de vida de los varones en este País hace plausible que un operado por HBP pueda ser reintervenido por neohiperplasia o diagnosticado de cáncer de próstata, con el paso del tiempo, hace que sea interesante poder aventurar con antelación esas posibilidades.

Con esta finalidad se han publicado ya dos trabajos $(2,3)$ y ha sido en el curso de los controles de estos 70 casos iniciales que nos hemos encontrado con los cuatro que son objeto del presente artículo que aunque pretende sólo la comunicación de una circunstancia "singular", lo cierto es que no hemos encontrado citas bibliográficas específicas en la consulta a "PubMed"aún en las referidas a los cambios del PSA después de la adenomectomía abierta, RTU y HoLEP (4-12).

\section{MATERIAL Y MÉTODO}

Como decíamos, hace algunos años iniciamos el estudio de la prostata residual de nuestros operados por vía abierta siguiendo el protocolo de obtener datos histológicos de la prostata residual en el mismo acto operatorio y, a medio plazo, entre 12 y 36 meses (por vía endoscópica con asa de resector). Obtuvimos datos morfométricos de la mis- ma mediante eco prostática transrectal al $3^{\circ}$ día del postoperatorio y aleatoriamente después en el curso de los 5 años de seguimiento y bioquímicos con PSA anuales durante el citado periodo. Como ya hemos indicado se han publicado los primeros resultados en las referencias ya citadas.

Ha sido, pues, en el curso de este seguimiento que nos hemos encontrado con 4 pacientes que tras un PSA inicial (al año de la cirugía) "indetectable" los controles anuales posteriores (uno a los 5 años, otro a los 4 y dos, a 3 años) han mantenido sin variación alguna el $<0.15 \mathrm{ng} / \mathrm{ml}$. en todos ellos.

Este hecho nos ha llevado a entresacar dichos casos para analizarlos desde los otros puntos de vista del trabajo con la intención de establecer, si los había, aspectos comunes o similares:

\section{Caso 1}

Varón de 71 años que, sin antecdentes de hepatopatía, desde 1998 refiere síndrome de LUTS de tipo obstructivo. En 2002 consta un PSA de 7,6 $\mathrm{ng} / \mathrm{ml}$ por el que se practicó biopsia de próstata con el resultado de "HBP y prostatitis crónica". En el tacto rectal se anotó "glándula mediana/grande sin nódulos". La ecografía transrectal demostró una glándula de $94 \mathrm{cc}$.

Dado el cuadro obstructivo se decidió cirugía abierta a la que llegó con un PSA de 6,35 ng/ml.

Se practicó ATH+VCP(Adenomectomía transcervical hemostática + Vesicocapsuloplastia) de una pieza operatoria que pesó 80 grs. La antomía patológica de la pieza confirmó el diagnóstico preoperatorio y la biopsia del tejido residual reveló "ausencia de tejido glandular con fragmentos de pared de vesículas seminales" (Figura 1).

La ecografía transrectal al $3^{\circ}$ día del postoperatorio demostró un tejido residual equivalente a $0,4 \mathrm{cc}$.

Fue seguido anualmente con PSA $1<0,15$ $\mathrm{ng} / \mathrm{ml}$ ) y a los 17 meses se obtuvo muestra histológica con el resector que demostró "ausencia de tejido glandular". Coincidiendo con esta biopsia se indicó una ecografía trasrectal que informó de "tejido residual post cirugía equivalente a 9 grs. de tejido". El último PSA a los 60 meses continúa "indetectable" $(<0,15 \mathrm{ng} / \mathrm{ml})$.

\section{Caso 2}

Varón de 66 años sin antecedentes de disfunción hepática y con historia de LUTS de 3 años de 


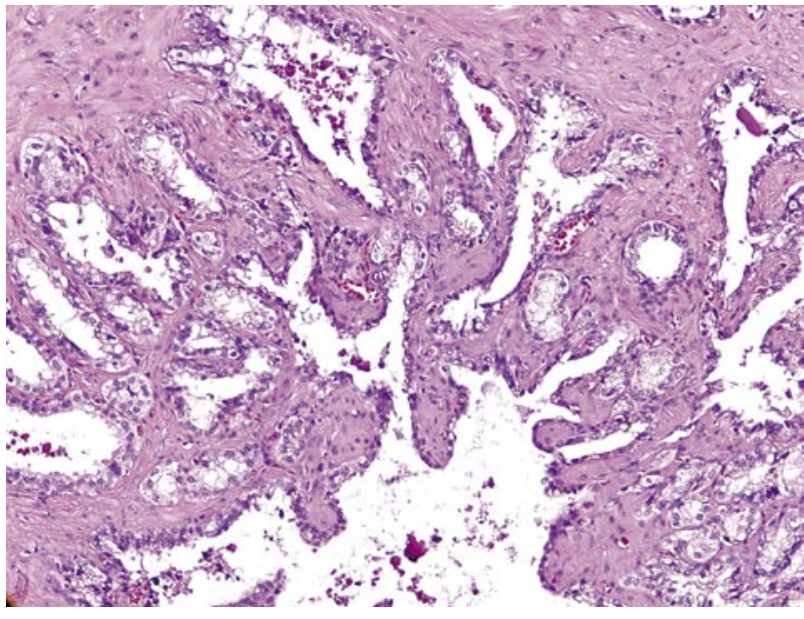

FIGURA 1. Biopsia, en el curso de la adenomectomía, de la "próstata residual" del Caso 1. La ausencia de tejido prostático hizo que se tomara parte de la pared de la vesícula seminal $(20 \times 0,5)$

evolución, sometido a cistoscopia por hematurias con resultado negativo a neoformación vesical pero que confirma lóbulos prostáticos obstructivos y sangrantes. Con un PSA preoperatorio de $8,72 \mathrm{ng} / \mathrm{ml}$ y una eco abdominal informando de glándula prostática de $86 c c\left(\dot{c}^{2}\right)$ se practicó ATH+VCP enucleando una próstata de 130 grs(i!) con hiperplasia nodular y una biopsia residual con "escasas glándulas". En la ecografía transrectal del 3 o día postoperatorio tuvimos "problemas técnicos" que nos impidieron disponer de la imagen... Los controles de PSA postoperatorio fueron siempre indetectables hasta los 53 meses en

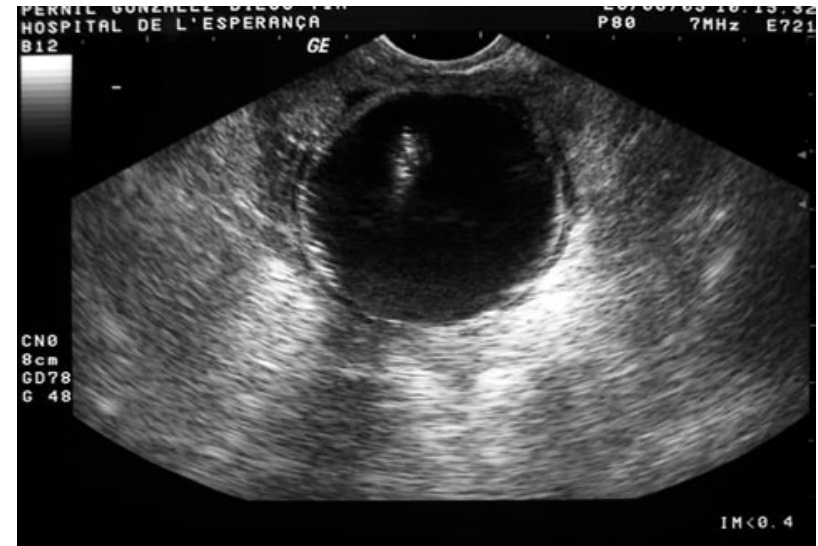

FIGURA 2. Ecografía transrectal al 3ํ día postoperatorio de la próstata del caso 2 ( 130 grs). Práctica ausencia de tejido cuantificable $(0,4 c c)$. Toda la celda aparece ocupada por el globo de la sonda.

que si pudimos realizar una ecografía transrectal con un tejido residual equivalente a unos 9 grs. (Figura 2). En este caso no dispusimos de la aquiescencia del paciente para realizar la biopsia lejana del tejido residual.

\section{Caso 3}

Varón de 76 años biopsiado en otro centro por PSA elevado $(\dot{2}$ ?) con resultado de "ausencia de neoplasia". Demostrada la repercusión obstructiva de su HBP con una eco abdominal que evidencia

TABLA I.

\begin{tabular}{|c|c|c|c|c|c|}
\hline Pieza A.P. & Histologia residual & EcoTR $3^{\circ}$ día & Bx medio plazo & EcoTR lejana & PSA \\
\hline $\begin{array}{l}\text { Caso 1: } 80 \text { grs. } \\
\text { Hiperplasia } \\
\text { Nodular }\end{array}$ & Ausencia glandular & Residual:0,4cc & $\begin{array}{l}\text { Ausencia } \\
\text { glandular }\end{array}$ & $\begin{array}{l}\text { Restos: } 9 \text { grs } \\
\text { a los } 4 \text { años }\end{array}$ & $\begin{array}{c}<0,15 \\
(60 \text { me.) }\end{array}$ \\
\hline $\begin{array}{l}\text { Caso 2: } 130 \text { grs. } \\
\text { Hiperplasia } \\
\text { Nodular }\end{array}$ & Escasas glándulas & No consta & No consta & $\begin{array}{l}\text { Restos: } 9 \text { grs } \\
\text { a los } 53 \text { meses }\end{array}$ & $\begin{array}{c}<0,15 \\
48 \text { meses }\end{array}$ \\
\hline $\begin{array}{l}\text { Caso 3: } 75 \text { grs. } \\
\text { Hiperplasia } \\
\text { Nodular }\end{array}$ & Atrofia+3 glándulas & No consta & No consta & Falta & $\begin{array}{c}<0,15 \\
\text { (36 me.) }\end{array}$ \\
\hline $\begin{array}{l}\text { Caso 4: } 150 \text { grs. } \\
\text { Hiperplasia } \\
\text { Nodular }\end{array}$ & Escasas glándulas & No consta & $\begin{array}{c}\text { Fibrosis+músculo } \\
\text { liso }\end{array}$ & $\begin{array}{l}\text { No se identi- } \\
\text { fican restos a } \\
20 \text { meses }\end{array}$ & $\begin{array}{c}<0,15 \\
(37 \text { me.) }\end{array}$ \\
\hline
\end{tabular}


una glándula prostática con lóbulo medio de 79 cc y un PSA de $1 \mathrm{ng} / \mathrm{ml}$ se procedió a la ATH+VCP extirpando una pieza adenomatosa de $75 \mathrm{grs}$. y con una biopsia residual de "atrofia con 3 pequeñas glándulas".

Las determinaciones del PSA se mantuvieron siempre a $<0,15 \mathrm{ng} / \mathrm{ml}$ hasta los 36 meses posteriores, con función hepática "normal".

\section{Caso 4}

Varón de 72 años. Prostatismo de varios años de evolución con PSA muy discretamente aumentados que no fueron valorados ante la prostatomegalia presente (129cc por eco transrectal) por lo que se indicó ATH +VCP que obtuvo una "pieza" de 151 grs. de "hiperplasia" mientras la biopsia residual sólo demostró "tejido fibroadiposo con prostatitis crónica". A los 19 meses dispusimos de histología del tejido residual por RTU con el resultado de "epitelio uretral, músculo liso, fibrosis y ausencia glandular" (Figura 3). La ecografía transrectal a los 18 meses no identificó "restos prostáticos cuantificables". Los PSA siguen indetectables a los 37 meses de la cirugía con enzimas hepáticos "normales".

\section{RESULTADOS}

El PSA producido por el componente epitelial prostático es vertido, por un lado a la luz glandular y, por otro, pasa al torrente circulatorio donde

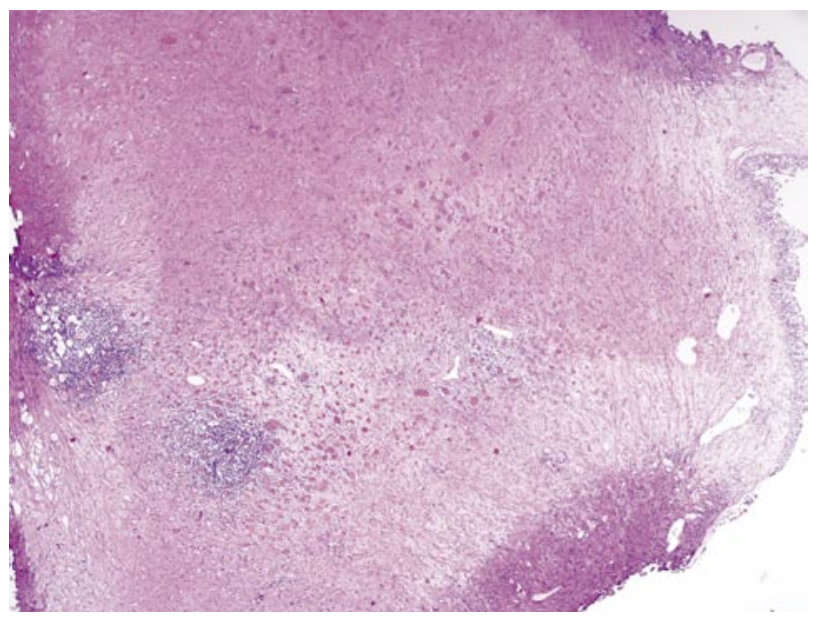

FIGURA 3. Biopsia con asa de resector a los 19 meses de la intervención de la glándula de 150 grs. Ausencia de tejido glandular, cambios de tejido de granulación vascular con algún infiltrado linfoide, inflamación crónica y nidos de Von Brunn $(4 \times 0,5)$. es determinado para obtener la cifra que solicitamos habitualmente al laboratorio.

Tenemos la máxima experiencia desde los $80^{\prime}$ en controlar el seguimiento del cáncer de próstata tratado con prostatectomía radical determinando el PSA periódico. La seguridad de haber sido efectivos con el tratamiento nos la da la tranquilidad de obtener cifras "indetectables" del antígeno $(<0.15)$ en todos los controles. La recidiva bioquímica de diversa importancia y entidad siempre vendrá relacionada con la pérdida de esa indetectabilidad.

¿Qué ocurre con la cirugía de la HBP? Según datos deducidos de nuestro propio estudio, la cirugía retropúbica de la HBP extirpa, por término medio, algo más del $80 \%$ de toda la glándula prostática quedando menos de un $20 \%$ residual constituido por tejido periférico y la cápsula. A su vez, en nuestra serie, el PSA tras la adenomectomía sufre un descenso medio del $83 \%$ de su valor preoperatorio. Existiendo pues una buena correlación entre ambas cifras, volumétrica y bioquímica, en toda la serie parece lógico esperarla también en estos cuatro casos "singulares".

El desarrollo de la HBP sabemos que parte de la zona transicional y periuretral y se expande hacia el exterior, sobre la zona periférica, y sobre la uretra. Parece lógico pensar que a mayor volumen transicional menor volumen periférico. Nuestros casos tienen de común haber sido "próstatas grandes", con escasa o nula presencia glandular en el tejido residual en la intervención y a medio plazo y que, en los casos de que disponemos de imágenes, se corresponde con una mínima representación ecográfica de la glándula.

Por todo ello nos parece verosímil la teoría de que en casos de gran desarrollo de la zona transicional con HBP podría llegarse a producir un rechazo tal de la zona periférica que por compresión e isquemia ocasionara su atrofia y "virtual" desaparición. La ausencia de PSA "detectable" debería ser interpretado como prueba de "radicalidad" traduciendo la ausencia de epitelio glandular generador.

La no obtención de datos bibliográficos en los que poder basar la real frecuencia de PSA "indetectables" después de adenomectomía retropúbica nos ha llevado a revisar los nuestros en el período 1994/2001 que estuvieran informatizados (184 sobre más de 1000 intervenidos). Sobre este total de 184 intervenciones hemos encontrado 2 casos de PSA $<0,15 \mathrm{ng} / \mathrm{ml}(1,04 \%)$. En sus historias clínicas consta seguimiento de 3 años y 19 meses, respectivamente, cerrándose en 1998 y no constan 
antecedentes de cirrosis hepática que, como es sabido, puede dar lugar a desequilibrios hormonales que favorezacn una feminización y pudieran explicar una descenso tan notable del PSA. Hemos pretendido conseguir un control actual de los mismos pero, aún contactando con ambos, sus edades actuales de 87 y 92 años y su dificultad de desplazamiento nos han hecho desistir de conseguirlo.

En el conjunto de las dos series tendríamos un índice de PSA indetectable después de esta cirugía del $(2,3 \%)$.

\section{CONCLUSIONES}

La determinación periódica del PSA en el seguimiento de pacientes intervenidos por HBP puede ser un excelente instrumento frente a la aparición de neopatologías en el tejido residual, tanto neohiperplasias como carcinoma.

Nuestro criterio actual se reafirma en que no puede mantenerse el "cut-of" de la próstata residual postquirúrgica en las cifras admitidas de $4 \mathrm{ng} / \mathrm{ml}$ para una próstata "no intervenida" $y$, por tanto, se hace preciso un mejor seguimiento de todos aquellos casos que presenten cifras crecientes de PSA y establecer un nivel de indicación de la biopsia más rigurosos que se podría establecer, en principio, en $2 \mathrm{ng} / \mathrm{ml}$. aunque teniendo presente la edad en que tal circunstancia se produjera y la relación de "densidad" del marcador.Tales criterios deberán ser refrendados por el oportuno estudio y seguimiento de nuevos pacientes que sean intervenidos por cirugía abierta de HBP.

\section{BIBLIOGRAFÍA y LECTURAS RECOMENDADAS ( ${ }^{*}$ lectura de interés $y^{* *}$ lectura fundamental)}

*1. Roehborn CG, Boyle P, Begner D, Gray T. et al. Serum Prostate Specific Antigen and prostate volume predict lon-term changes in symptons and flow rate: Results a four year, randomized trial comparing finasteride vs placebo. PLESS Study Group, Urol, 1999; 54, 662-9.

*2. Ballesteros Sampol JJ, Royo Lázaro J, y Lloreta Trull J. Hallazgos histomorfométricos de la próstata residual y celda prostática tras la cirugía retropúbica por HBP (I): Datos basales obtenidos en los últimos 70 casos consecutivos. Arch Esp Urol, 2007; 60, 1069-76.
*3. Ballesteros Sampol JJ y Lloreta Trull J. Hallazgos bioquímico-Histomorfométricos de la próstata residual (II): Comportamiento del PSA, a largo plazo, tras adenomectomía retropúbica por HBP. Interrelaciones con el volumen e histología de la próstata residual y sus implicaciones en el diagnóstico ulterior de adenocarcinoma. Arch Esp Urol, 2009; 62 (09): 713-8.

*4. Lloyd S N, Collins GN, McKelvie GB, Heir M, et al. Predicted and actual change in serum PSA following prostatectomy for BPH. Adult Urol, 1994; 43 (4): 472-8.

*5. Ravery V, Meulemans A y Boccon-Gibod L. Clearance of free and total serum PSA after prostatic surgery. Eur Urol, 1998; 33, 251-4.

6. Scattoni V, Raber M, Montorsi F, Da Pozzo L, et al. Percent of free serum PSA and histological findings in patients undergoing open prostatectomy for Bening Prostatic Hyperplasia. Eur Urol, 199, 36, 621-30.

7. Furuya Y, Akakura K, Toyofusa T, Tomohiko I, et al. Changes in serum prostate-specific antigen following prostatectomy in patients with Bening Prostatic Hyperplasia. Int J Urol, 2000; 7: 44751.

*8. Özden C, Inal G, Adsan Ö Yasici S, et al. Detection of Prostate cancer and changes in PSA six months after surgery for Bening Prostatic Hyperplasia in patients with elevated PS". Urol, 2003; $71,150-3$

9. Marks L S, Dorey F J, Rhodes T, Shery E D, et al. Serum prostate specific antigen levels after tranurethral resection of prostate: A longitudinal characterization in men with benign prostatic hyperplasia. J Urol, 1996; 153, 1035-9.

*10. Iraoka Y, Shimizu Y, Takahashi H and Abe H. Trial of complete detachement of the whole prostate lobes in benign prostate hyperplasia by transurethral enucleation of the prostate. Utol Int, 2007; 79 (1), 50-4.

*11. Tinmouth W W, Habib E, Kim S C, Kuo R L and al. Change in serum prostate specific antigen concentration after holmium lasser enucleation of the prostate: a marker for completeness of adenoma resection?. J Endourol, 2005; 19, 550-4.

12. Cetinkaya M, Ulusoy E, Aki T, Kosan M and al. Effect of transurethral resection on serum free/total prostate-specific antigen levels in patients with benign prostatic hyperplasia. Urol, 1999; 53, 11820. 